\title{
Observing Collaboration:
}

\section{Group-Centered Design}

\section{Saul Greenberg}

\author{
University of Calgary, Calgary, Canada
}

It is the late 1980s. Along with a other technologists, I was just getting interested in the new discipline of Computer Supported Cooperative Work (CSCW), where my focus was on how geographically distributed groups could work together in real time over a shared visual workspace. In that era, groupware design was mostly by the seat of our pants; what we built was often a consequence of balancing our intuitions about the collaborative process against technical considerations.

John Tang's PhD dissertation (Tang, 1989) and his various derivative publications (e.g., Tang, 1991) changed my view of groupware design, as it introduced the notion of 'group-centered' design. 
John, who was interning at Xerox PARC, was interested in technical support for small design groups. Instead of just building technology, he decided to observe, describe, and quantify how small groups actually worked together on conceptual design tasks when interacting over shared visual work surfaces such as a whiteboard or table. His approach was strongly influenced and supported by the user-centered researchers at the Xerox PARC System Sciences Laboratory: Deborah Tatar, Sara Bly, Scott Minneman, Lucy Suchman, and Austin Henderson. PARC had also just created some seminal meeting room systems and were investigating how people interact through video.

\section{Observational Studies of Shared Work Surfaces}

In 1988, Sara Bly performed an observational study of a pair of collaborators that challenged the intuitive "conventional” view of the communal work surface as a medium for creating and storing a drawing artifact. She saw that the drawing

process - the actions, uses, and interactions on the drawing surface-were as important to the effectiveness of the collaboration as the final artifact produced (Bly, 1988). She also noticed that allowing designers to share drawing space activities increased their attention and involvement. John extended Bly’s findings by studying small design groups, who used large sheets of paper as a shared work surface. Some teams placed the paper on a table, while others tacked it to a whiteboard. He made several important observations. 
Orientation. Drawings made on the table-mounted paper were oriented in different directions. Although people had greater difficulty drawing and perceiving the images, orientation proved a resource for facilitating the meeting. Because drawings faced a particular person, a context and an audience were established. Marks made by participants that were aligned to an image conveyed support and focus. People working on their own image used orientation as an informal "privacy" boundary until they were ready to call in the group’s attention. The group using whiteboard mounted paper did not exhibit these behaviors. Proximity. When participants were huddled around the table-mounted paper, the sketchpad played a key role in mediating the conversation. This role was lessened in the whiteboard situation where people were seated several feet away.

Simultaneous Access. Given good proximity, a high percentage (45-68\%) of work surface activity around the tabletop involved simultaneous access to the space by more than one person.

John then built a descriptive framework to help organize the study of work surface activity, where every user activity was categorized and quantified according to what action and function it accomplished (Tang 1989, 1991). Actions included listing of spatially independent alpha-numeric notes, drawing of graphical objects, and communicative gestures over the surface. Functions include storing information for later recall, expressing ideas as one works over the surface, and mediating interaction through turn-taking and by focusing attention. 
While this framework seems overly simplistic compared to what is now known, its purpose at the time was to draw attention to the amount of group interactions not supported by the CAD and group computer tools of that era. John's classification of small group activities within this framework revealed that the "conventional” view of work surface activity—storing information by listing and drawing — constituted only $25 \%$ of all work surface activities. Expressing ideas and mediating interaction comprised the additional $\sim 50 \%$ and $\sim 25 \%$ respectively. Gesturing, which is often overlooked as a work surface activity, played a prominent role in all work surface actions ( $\sim 35 \%$ of all actions). For example, participants enacted ideas by using gestures to express them, and gestures were used to signal turn-taking and to focus the attention of the group. From these observations, he derived various design criteria that shared work surface tools should support. He stressed the importance of allowing people to gesture to each other over the work surface, and emphasized that the process of creating a drawing is in itself a gesture that must be shown to all participants through continuous, fine-grained feedback. Another key point was that the tool must not only support simultaneous activity, but also encourage it by giving participants a common view of the work surface. 


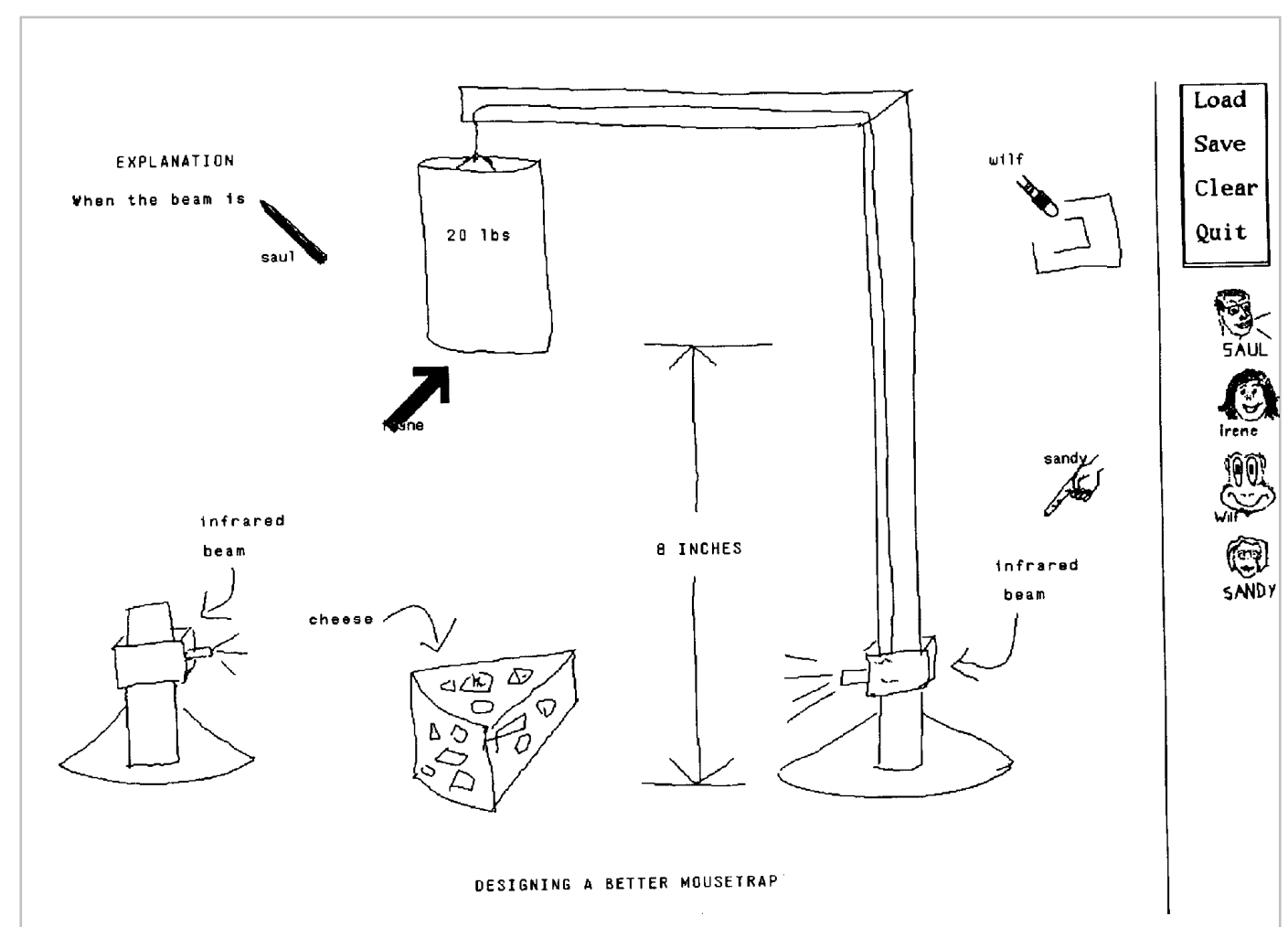

Figure 1 GroupSketch, from (Greenberg, et. al., 1992)

\section{System Building}

As these results were coming out, other groups were building multi-user sketching and drawing systems. I and a variety of students (Ralph Bohnet, Dave Webster, Mark Roseman) immediately latched onto John’s design principles. We created a distributed groupware bitmap sketching system called GroupSketch, illustrated in Figure 1 (Greenberg, et. al., 1992). Its features directly embodied John’s design 
suggestions: each person had a large labeled cursor whose image reflected gesturing, pointing (for attention) and drawing acts, marks made by a person were immediately visible to all, and people could gesture and draw simultaneously. Later versions included the functionally richer XGroupSketch and the objectoriented GroupDraw systems. What was exciting to us was that these systems felt 'right'; people (including artists) could use it immediately and could dive down into their shared drawing tasks.

Other researchers developing parallel systems were also informed by John's ideas. Commune was a pen-based distributed tabletop system and - like GroupSketch - had multiple cursors, immediate display of all actions, and allowed simultaneous activity. VideoDraw and VideoWhiteBoard from PARC (Tang and Minneman, 1990 \& 1991) and TeamWorkStation from NTT, Japan (Ishii, H. and Kobyashi, M. 1993), were video-based drawing systems and worked by fusing video images. Figure 2 illustrates two of them, how they are built, and how people could actually see each other's arms, body shadows, pens, and drawing marks in the image. What was notable is that these and several other systems - even though based on quite different technologies - had the same fluid feel to them. The common human factors of their design transcended their implementations. 

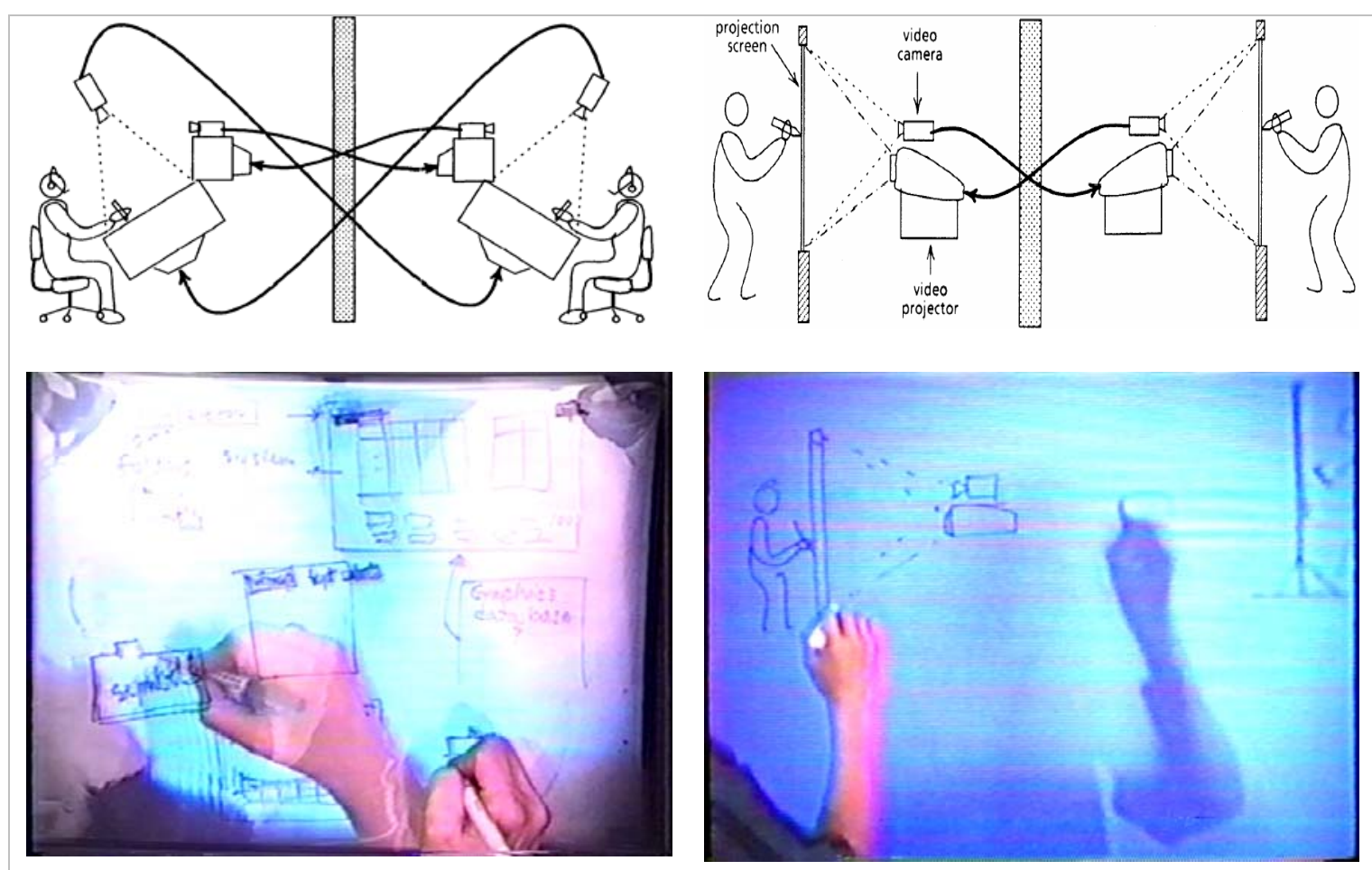

Figure 2. The two images on the left show how VideoDraw works (Tang \& Minneman, 1991a). On the right, the two images show how VideoWhiteboard works (Tang \& Minneman, 1991b), , with permission from John Tang.

While John’s observations and design principles may appear self-evident, many related commercial and research groupware systems of that era (and even today) have failed to live up his criteria. Many had no pointers, which meant people could not gesture around the surface. Neither did participants see each others' actions as they occurred, for actions were not broadcast until a complete graphical stroke was made or a complete text line entered. This meant that people’s talk around their drawing act did not make much sense. In contrast to the systems based on John's guidelines, interactions on these systems felt 'dead'. 


\section{Influencing the Future}

John's observational work set the tone for much of the shared workspace research in the 1990s. In our lab, we built both distributed and single display groupware toolkits (e.g., GroupKit, SDGToolkit) that tried to generalize some of his

principles, so that programmers had capabilities such as simultaneous actions and multiple cursors 'for free'. We organized a workshop on real time drawing, which resulted in a book (Greenberg, Hayne,and Rada, 1995). We also started a new research program on workspace awareness; we observed the subtleties of how people kept track of what others were doing when working face to face over a drawing, then invented mechanisms that let people recreate this awareness when working over distance (Gutwin and Greenberg, 2002), and finally generalized these as a set of human factors principles articulating the basic mechanical process that define most collaborative acts over a workspace (Pinelle, Gutwin, and Greenberg 2003).

At the same time, new systems and techniques came out that further leveraged John’s work. Several were modeled after people drawing on opposite sides of a piece of glass: Ishii and Kobyashi’s Clearboard (1993), Apperley’s LIDS (2003) and our own VideoArms (Tang, Neustaedter and Greenberg, 2006). Figure 3 shows the later, where we see two groups of multiple collocated people working across two distributed connected surfaces; other people’s arms are clearly visible. The groupware community was also busy examining the social 


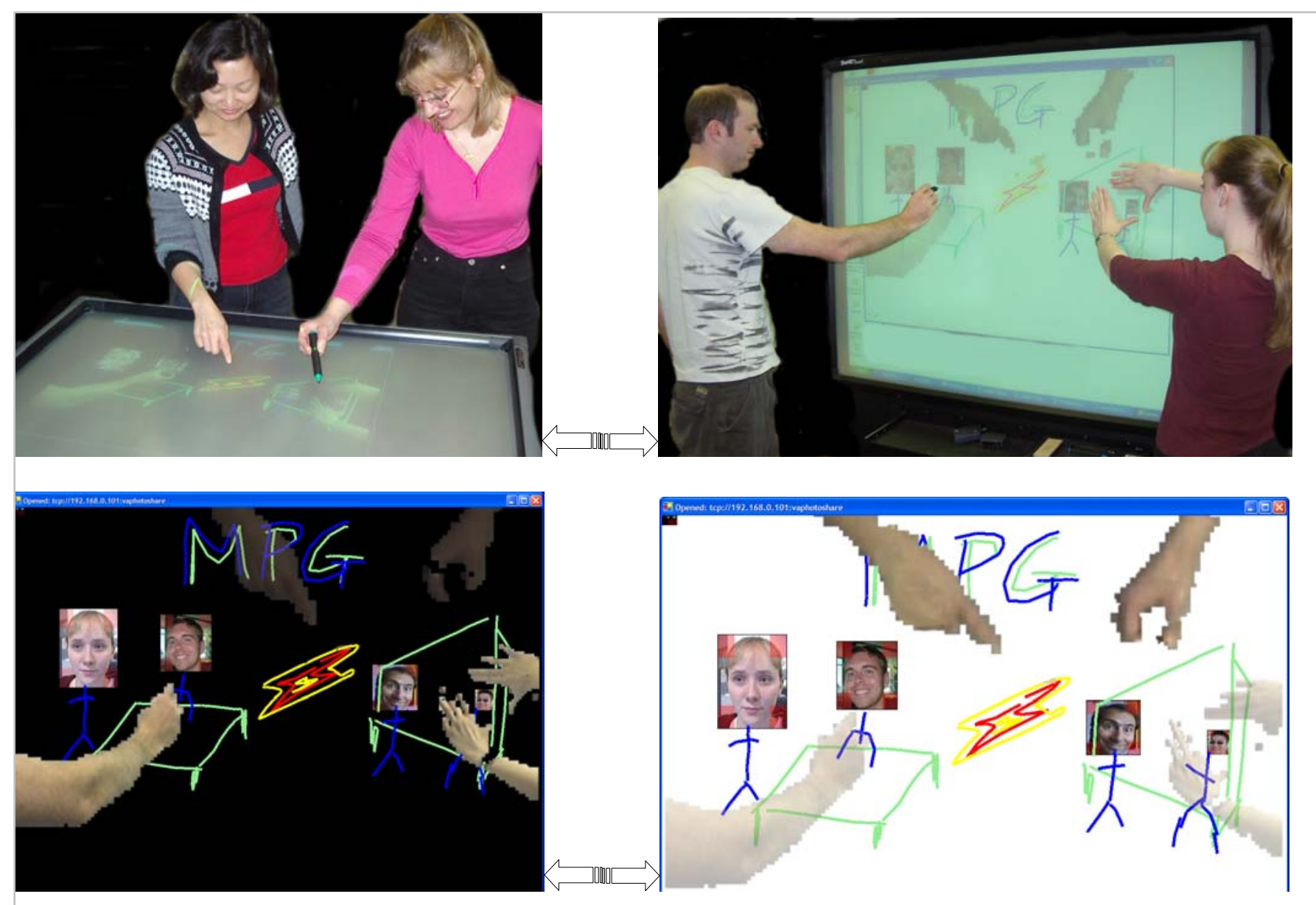

Figure X.3. VideoArms in action, showing two groups of two people working over two connected displays (top) and a screen grab of each surface (bottom).

psychology literature, which proved to have much fertile information in it that

added richness to John's basic observations. More recently, researchers on digital

tables for co-located collaborators also revisited and extended John's work. For

example, Sheelagh Carpendale and her group performed further observational

studies of how people use the orientation of artifacts as a resource on a table, and

how people partition a space into personal and group territories (e.g., Kruger, et.

al. 2004). 
The Established Paradigm: Observe, Generalize, Design

On reflection, John's work proved important to me, my research group, and the community at large for two reasons. First, it laid the foundations for the basic human factors in shared visual workspaces, factors that could not only be exploited in system design, but that served as an insight into other human factors that should be considered. Second - and this is more important - it provided an early example of a robust process for groupware development. Beyond the taskoriented observations of single user systems, groupware design must begin with observations of actual working practices. Initial observations will usually expose the major factors that comprise not only group task activity, but group processes as well. This suggests ways that factors can be organized and quantified, and reveal nuances of other factors that could be revisited in later, more detailed observations.

Defining human factors of collaboration is the key. Design based on these factors should transcend the technology in terms of the collaborative experience it offers the group. As with John's original observations, these factors will have a long 'shelf life'; people's collaborative practices today are generally the same as they were 17 years ago. In contrast, systems and underlying technologies have come, evolved, and been replaced. 


\section{References}

Bly, S. 1988. A use of drawing surfaces in different collaborative settings. In Proc. Conf Computer-Supported Cooperative Work, 250-256, ACM Press.

Greenberg, S., Roseman, M., Webster, D. and Bohnet, R. 1992. Human and technical factors of distributed group drawing tools. Interacting with Computers, 4(1):364-392. Butterworth-Heinemann.

Greenberg, S., Hayne, S., and Rada, R., eds 1995. Groupware for Real-Time Drawing: A Designer's Guide. England:McGraw-Hill Book Company.

Gutwin, C., and Greenberg, S. 2002. A Descriptive Framework of Workspace Awareness for Real-Time Groupware. Computer Supported Cooperative Work, 11(3-4): 411-446, Kluwer Academic Press.

Ishii, H. and Kobyashi, M. (1993). Integration of interpersonal space and shared workspace: Clearboard design and experiments. ACM Transactions on Information Systems, 11 (4): 349-375, ACM Press.

Kruger, R., Carpendale, S., Scott, S. and Greenberg, S. 2004. Roles of Orientation in Tabletop Collaboration: Comprehension, Coordination and Communication. Journal of Computer Supported Collaborative Work 13(5-6):501-537. Klewer.

Pinelle, D., Gutwin, C. and Greenberg, S. 2003. Task Analysis for Groupware Usability Evaluation: Modeling Shared-Workspace Tasks with the 
Mechanics of Collaboration. ACM Transactions on Human Computer Interaction, 10(4): 281-311, ACM Press.

Tang, A., Neustaedter, C. and Greenberg, S. 2006 - In Press. VideoArms: Embodiments for Mixed Presence Groupware. In Proc $20^{\text {th }}$ BCS-HCI British HCI 2006 Group Conference.

Tang, J. (1989) Listing, drawing, and gesturing in design: a study of the use of shared workspaces by design teams. PhD Thesis, Dept mechanical Engineering, Stanford University, USA. Also as Report SSL-89-3, Xerox PARC.

Tang, J., 1991. Findings from Observational Studies of Collaborative Work. International Journal of Man-Machine Studies, 34(2):143-160, Academic Press.

Tang, J. and Minneman, S. 1990, VideoDraw: A Video Interface for Collaborative Drawing, In Proc Conference on Human Factors in Computing Systems, 313-320, ACM Press.

Tang, J. and Minneman, S. 1991. VideoWhiteboard: Video Shadows to Support Remote Collaboration, In Proc Conference on Human Factors in Computing Systems, 315-322, ACM Press. 